

\section{Os indicadores da alfabetização cartográfica. Pensando convergências entre a cartografia escolar e $o$ pensamento espacial}

Indicadores de alfabetización cartográfica: pensar convergencias entre la cartografía escolar y el pensamiento espacial

Indicators of Cartographic Literacy. Thinking Convergences between School Cartography and Spatial Thinking

Márcia Cristina Urze Risette*

\begin{abstract}
Resumo
O artigo que estamos apresentando realiza uma aproximação teórica e conceitual entre a cartografia escolar e o pensamento espacial. 0 objetivo dessa exposição foi encontrar convergências entre ambas as temáticas, delineando os principais conceitos e habilidades que as compõem. A partir disso, tendo os Indicadores da Alfabetização Científica como referência, propomos e apresentamos para reflexão e debate entre os pares os Indicadores da Alfabetização Cartográfica.
\end{abstract}

\section{Palavras-chave}

Cartografia escolar; pensamento espacial; geografia; alfabetização científica.

* Universidade de São Paulo. 


\section{Resumen}

El artículo presenta un enfoque teórico y conceptual a la cartografía escolar y el pensamiento espacial. El objetivo de esta exposición es encontrar convergencias entre ambos temas, delineando los principales conceptos y habilidades que los componen. Enconsecuencia, teniendo los Indicadores de Alfabetización Científica como referencia, proponemos y presentamos los Indicadores de Alfabetización Cartográfica para la reflexión y discusión entre los pares.

\section{Abstract}

This article presents a theoretical and conceptual approach to school cartography and spatial thinking. The purpose of the study was to find convergences between both topics, outlining the main concepts and skills which compose them. Consequently, having the Scientific Literacy Indicators as a reference, we propose and present the Indicators of Cartographic Literacy for peer reflection and discussion.

\section{Palabras clave}

Cartografía escolar; pensamiento espacial; geografía; alfabetización científica.

\section{Keywords}

School cartography; spatial thinking; geography; scientific literacy. 


\section{Apresentação da pesquisa}

O trabalho que estamos apresentando é parte de pesquisa desenvolvida durante o mestrado realizado na Faculdade de Educação da Universidade de São Paulo defendido em 2017. A pesquisa trata-se da proposição de Indicadores para a Alfabetização Científica ${ }^{1}$ na Educação Geográfica, os quais foram elaborados a partir dos conceitos desenvolvidos nos campos de conhecimento da Cartografia Escolar, do Pensamento Espacial e do Raciocínio Geográfico. 0 estudo foi desenvolvido visando estabelecer os principais conceitos dessas três áreas de investigação, delineando os métodos e as estratégias para a elaboração dos indicadores, e tendo como parâmetro a proposição dos Indicadores da Alfabetização Científica realizada por Sasseron (2008) e por Sasseron e Carvalho (2008).

O objetivo, portanto, foi compreender como ocorre o processo de Alfabetização Científica na Educação Geográfica elaborando e identificando novos e indicadores existentes nas atividades desenvolvidas em uma escola estadual situada em Itaquera, Zona Leste da Capital Paulista, durante os anos de 2008 e 2009. Dessa forma, a escolha por entender como a Cartografia Escolar pode contribuir para a proposição de Indicadores da Alfabetização Científica na Educação Geográfica se deu por duas razões: a primeira foi porque a Sequência Didática que estruturava as atividades analisadas tinha como fundamento os pressupostos da Cartografia Escolar; a segunda porque os conceitos a serem compreendidos e ensinados aos alunos de acordo com os preceitos da Cartografia Escolar aparecem também nas proposições do Pensamento Espacial.

O Pensamento Espacial, está no campo da cognição, as habilidades propostas podem ser utilizadas por todas as áreas do conhecimento, sendo estimulado por meio das estratégias didáticas utilizando não apenas os conceitos que estruturam a Geografia como também a linguagem cartográfica. O Raciocínio Geográfico, como pensamos geograficamente, como lemos o mundo, tem base epistemológica e significa compreender a realidade por meio do conhecimento geográfico.

Ao analisarmos o processo de Alfabetização Científica e associarmos ao raciocínio geográfico estamos compreendendo o papel das categorias, princípios e conceitos da Educação Geográfica, organizando e estruturando os conceitos fundantes e essenciais da disciplina e os apresentando aos alunos com base nas habilidades primordiais da Geografia. Essa estratégia didática aproxima os estudantes dos métodos científicos da Geografia, sendo a cartografia um deles, e, dessa forma, proporciona o desenvolvimento do raciocínio crítico, a compreensão da complexidade concreta e a construção do senso de cidadania no indivíduo.

Esse artigo tem por objetivo articular a Cartografia Escolar e o Pensamento Espacial estabelecendo, em seguida, os indicadores advindos

\footnotetext{
1 Em alguns momentos vamos substituir o termo Alfabetização Científica por AC,
} para proporcionar maior fluidez à leitura. dessa relação. Tal proposição merece, portanto, uma análise sobre quais conceitos e habilidades podem ser adicionados ou subtraídos e quais avanços podemos realizar a partir dessa proposta.

\section{A articulação entre o pensamento espacial e a cartografia escolar}

O contato atual com ferramentas e aplicativos que utilizam de informação geoespacial tem facilitado o acesso às ferramentas cartográficas, ampliando assim o arcabouço da alfabetização espacial dos usuários, uma vez que esses recursos estão nas mãos da população: no celular, utilizados o tempo todo. Vários aplicativos exigem o acesso à nossa geolocalização para nos dar a informação de que precisamos, seja procurando restaurantes, seja postando a localização em que estamos ou do lugar que visitamos no Facebook, seja compartilhando informação a respeito dos serviços de um restaurante, ou para medir as distâncias que caminhamos facilitando o controle da nossa saúde, seja para nos locomovermos em lugares que não conhecemos muito bem, ou para utilizar a câmara fotográfica do aparelho, entre outros usos.

Acessamos mapas e encontramos lugares que desejamos frequentar a um clique de nossas mãos, sabemos as condições climáticas e programamos nossas vestimentas para o dia seguinte caso iremos viajar. Todos esses recursos contribuem para que tenhamos maior consciência da Alfabetização Espacial (Bednarz e Kemp, 2011). Assim, o domínio desses mecanismos e o uso completo das funções disponíveis em um aplicativo, como o Waze e o compartilhamento da localização pelo WhatsApp por exemplo, têm facilitado o acesso das pessoas às informações geográficas, atribuindo valor à localização das pessoas. Onde elas foram?, lugares que conhecem? O fato de ter acesso a essas informações estimula as pessoas a compartiIhá-las nas redes sociais. Saber utilizar essas informações de forma consciente como registro de abusos, de qualidade de atendimento (se o prato que chegou à mesa não foi o pedido e o restaurante se nega a reparar o equívoco, por exemplo), de maus tratos de funcionários, de divulgação enganosa, são meios possíveis atualmente para o exercício da cidadania.

Dessa forma, concordamos com Bednarz e Kemp (2011) quando afirmam que "a localização importa cada vez mais e mais devido às melhorias realizadas em dispositivos e serviços baseados na localização, a alfabetização espacial está se tornando fortemente vinculada à cidadania ${ }^{2}$ " (p. 19). Todos esses serviços oferecidos usam dados e informações geográficas (como o tripAdvisor, aplicativo de compras de supermercado próximos a sua localização, aplicativo de mapeamento de roubo: onde fui roubado, entre outros), nos permitindo mapear lugares de nosso interesse, desenhar trajetos e nos familiarizarmos cada vez mais com o mapa e seus componentes cartográficos. Atualmente, o usuário de

2 Tradução nossa. 
forma intuitiva desenha caminhos e traça planos de rotas e percursos. O que significa dizer que os dispositivos tecnológicos a que recorremos cotidianamente nos exigem sermos alfabetizados espacialmente, como observamos nessa definição:

Todos eles representam formas espaciais de ver o mundo e de resolução de problemas do nosso dia a dia, e demandam certas habilidades da parte do usuário, por exemplo, uma habilidade de capturar e comunicar conhecimento na forma de mapa, compreender e reconhecer o mundo visto de cima, reconhecer e interpretar padrões, ter conhecimento de que a Geografia é mais do que uma lista de lugares na superfície da Terra, ver o valor da Geografia como a base para organizar e descobrir informação, e compreender alguns conceitos básicos como escala e resolução espacial. Juntos, equivalem ao que podemos chamar de alfabetização espacial, um conjunto de habilidades relacionadas ao trabalho e ao raciocínio no mundo espacial e à capacidade de fazer uma imagem realmente valer mil palavras ${ }^{3}$ (Goodchild, 2006, p. 1).

A citação de Goodchild (2006) traz a definição de alfabetização espacial, a qual se trata do desenvolvimento de habilidades requeridas para o desenvolvimento do pensamento espacial, além disso, Goodchild (2006) ao falar da comunicação por meio do mapa, da visão vertical, da identificação de padrões espaciais e da resolução espacial e da escala, esclarece que as habilidades cartográficas estão inseridas no processo de alfabetização espacial. Essa articulação auxilia a pensar na relação entre a alfabetização cartográfica com o pensamento espacial. Nesse sentido, cabe valorizarmos os pesquisadores brasileiros que muito já avançaram a respeito da alfabetização cartográfica, como bem nos explica Duarte (2017) ao afirmar que:

Toda essa produção dos anos de 1980 e 1990 configurou um perfil à Cartografia Escolar brasileira fortemente assentado no referencial piagetiano e que consolidou a preocupação de se pensar a linguagem cartográfica como um duplo de conteúdo e metodologia essencial para o ensino da Geografia. Além disso, sedimentou o entendimento de que o processo de domínio dessa linguagem deve estar preocupado com as dimensões cognitivas correlatas a esse tipo de aprendizagem e devem estar fundamentadas em sólida teoria e fundamentação conceitual (p. 197).

A alfabetização cartográfica é entendida por grande parte desses pesquisadores ${ }^{4}$ como uma metodologia de ensino capaz de desenvolver o raciocínio geográfico e o pensamento espacial na criança, além de ser também uma forma de linguagem e de representação que deve ser ensinada aos

\footnotetext{
3 Tradução nossa.

4 Uma obra que sintetiza na forma de artigos a contribuição desses estudiosos é o livro Cartografia Escolar organizado pela professora Rosangela Doin de Almeida (2010), o qual compreende as contribuições das professoras Lívia de Oliveira, Tomoko Paganelli, Maria Elena Simielli, Janine Le Sann, Regina Araújo de Almeida, Elza Passini, e do professor Marcelo Martinelli, todos com contribuições, de forma geral, em produção de artigo, em teses, dissertações e orientações de pós-graduação na area de cartografia escola
}

alunos da Educação Básica para saberem ler e compreender melhor os mapas e, assim, entender o mundo em que vivem, apreendendo de forma mais clara e com mais sentido os conteúdos e conceitos da Geografia.

Nesse sentido, a alfabetização espacial deveria estar presente na educação básica, assim como os teóricos da alfabetização cartográfica têm defendido a incorporação dessa abordagem nos livros didáticos. De acordo com Goodchild (2006) a alfabetização espacial é tão essencial quanto ensinar a ler, a escrever, e a calcular matematicamente. Castellar (2017) nos elucida, inclusive, a respeito da relação do raciocínio lógico matemático com o desenvolvimento da relação espaço-tempo ao expor que o pensamento lógico-matemático "é uma estrutura necessária para a abstração simples em todos os níveis do desenvolvimento da criança, criando conexões entre os objetos semelhantes e suas propriedades físicas, por exemplo" (p. 210). Em seguida a autora esclarece como a cartografia escolar está associada com o raciocínio lógico-matemático e às relações espaço-temporais, explicando que o primeiro é o que possibilita a organização cognitiva dos objetos no espaço e a segunda é a qual permite pensar sobre as dimensões espaço temporais em que as coisas existem.

Isso significa dizer que para compreender como os objetos se organizam de forma espacial e temporal nós precisamos desenvolver o raciocínio lógico matemático, e a cartografia exerce função fundamental nesse processo. Para explicar melhor essa relação recorremos ao fluxograma elaborado por Simielli (2007), demonstrando a relação existente entre o desenvolvimento das habilidades cognitivas e a compreensão da linguagem cartográfica.

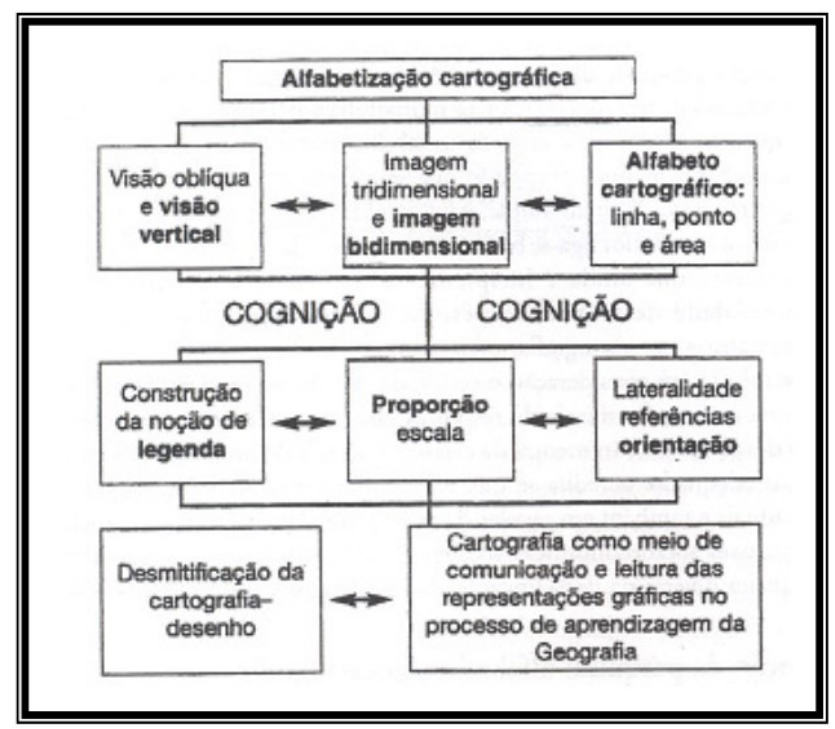

Figura 1. Fluxograma da Alfabetização cartográfica.

Fonte: Simielli (2007). 
A partir desse fluxograma entendemos que o aluno é alfabetizado cartograficamente quando ele aprende a visualizar os objetos a partir da visão vertical ${ }^{5}$ e, com isso, compreendendo como transformar esses objetos tridimensionais em uma imagem bidimensional (como também propõe Golledge, 2002) e a representá-los por meio do alfabeto cartográfico (linha, ponto e área). Para Simielli (2007) todas essas aprendizagens estão relacionadas entre si, no sentido de que ao apreender uma delas o aluno terá construído o raciocínio que o levará a assimilar a outra e vice-versa.

Tais conhecimentos estão vinculados com o desenvolvimento cognitivo, e quando eles estão suficientemente amadurecidos o estudante logo consegue construir uma legenda, desenhar com proporção e com noção de escala, e ter a noção de lateralidade, estabelecendo pontos de referência, e se localizando a partir das orientações geográficas. Essas habilidades cognitivas, que são tão importantes para o aprendizado da linguagem cartográfica, são desenvolvidas de forma que uma está intrinsecamente relacionada com a outra.

Por fim, quando o aluno assimila todas essas habilidades é que ele está alfabetizado cartograficamente, já que é capaz de desmistificar a cartografia-desenho, pois nesse momento ele entende e apreende a "Cartografia como meio de comunicação e leitura das representações gráficas no processo de aprendizagem da Geografia" (Simielli, 2007, p.90). É interessante observar que a proposta de Simielli em 2007 dialoga com a de Golledge (2002), pois esse autor propõem o desenvolvimento de habilidades do Pensamento Espacial que dialogam com o fluxograma da Alfabetização Cartográfica de Simielli (2007).

No documento Leanirng to Thinking Spatially (Aprendendo a Pensar Espacialmente) elaborado por diversas comissões de pesquisa científica e geográfica dos Estados Unidos (sendo o grupo de autoria principal o $N R C^{6}$ ), podemos verificar as habilidades que um estudante alfabetizado espacialmente domina, são elas:

- Ter estratégias cognitivas para pensar espacialmente-sabem onde, quando, como e por que pensar espacialmente.

- Praticar o Pensamento Espacial de forma esclarecida-possuem um conhecimento amplo e profundo de conceitos e de representações espaciais, comandam o raciocínio espacial, usando uma variedade de estratégias cognitivas para agir espacialmente, possuem capacidades espaciais bem desenvolvidas no uso ferramentas de suporte e tecnologias.

\footnotetext{
5 A visão vertical é quando o aluno consegue elaborar o desenho do ponto de vista de cima do objeto. A importância da representação na visão vertical é que essa visão exige uma abstração maior, permite uma visão da totalidade dos elementos a serem representados e é o ponto de vista utilizado para se elaborar um mapa.

6 NRC - Sigla em inglês para Conselho Nacional de Pesquisa (National Research Council), esse documento Learning to Think Spatially possui grande representatividade nas Universidades e na elaboração do programa curricular da Educação básica dos Estados Unidos.
}

- Adotar uma posição crítica para o Pensamento Espacial-eles podem avaliar a qualidade dos dados espaciais com base na sua fonte de pesquisa, com provável precisão e confiabilidade; eles podem usar dados espaciais para construir, articular e defender uma linha de raciocínio ou ponto de vista na resolução de problemas e na resposta a perguntas; e eles podem avaliar a validade dos argumentos com base em informações espaciais (National Research Council, 2006, p.20) ${ }^{7}$.

Assim, ser alfabetizado espacialmente exige que a pessoa saiba onde, como, quando e porquê utilizar o Pensamento Espacial; saiba identificar os conceitos e compreender as representações espaciais, utilizando inclusive ferramentas tecnológicas de forma mais consciente; e saiba questionar as informações recebidas averiguando a veracidade delas e verificando suas fontes, bem como construir argumentos com base em informações espaciais; além de dominarem também a habilidade de organizarem os objetos no tempo e no espaço (o raciocínio lógico matemático)

Nesta perspectiva, podemos afirmar que a alfabetização cartográfica assim como a alfabetização espacial possuem algumas habilidades cognitivas comuns (como escala, desenho bi/tridimensional, orientação e direção, e pontos, redes e regiões [ponto, linha e área]), ou seja, o objetivo da aprendizagem é o mesmo de ambas as propostas, a questão é que o Pensamento Espacial não está só na forma de ensino pelo mapa, mas também na proposta de desenvolver os demais conceitos e conteúdos geográficos nas aulas de Geografia.

A partir dessas reflexões, portanto, precisamos considerar o avanço da alfabetização espacial em relação à alfabetização cartográfica, visto que a primeira além de trazer uma nova abordagem cognitiva pautada no desenvolvimento neurológico, ela define os conceitos e os conteúdos que precisam ser desenvolvidos na Educação Geográfica. Ou seja, o Pensamento Espacial requer a alfabetização cartográfica e muitas outras funções cerebrais para ser desenvolvido. Além disso, há estudos que demonstram que crianças as quais tiveram lições estruturadas a partir das habilidades do Pensamento Espacial melhoraram a pontuação nas provas de matemática e de leitura (Gersmehl, 2008). 0 artigo Alfabetização em Geografia de Castellar (2000) já indicava a relação da alfabetização cartográfica com uma possível melhora no desenvolvimento da linguagem e da escrita ao relacionar o significante com o significado para a construção da legenda.

Sobre a relação do significante com o significado, recorremos às noções de semiologia gráfica apresentadas por Simielli (2007) a fim de compreendermos como ocorre a relação dos signos com o objeto real (que existe na realidade) que esse representa. 0 signo representa um objeto e aquele só pode representar esse no momento em que o leitor produz

\footnotetext{
7 Tradução nossa.
} 
em sua mente outro signo, considerando então, que o significado de um signo é outro signo. Assim, o signo possui dois aspectos: o significante e o significado. A autora esclarece que o significante é o aspecto concreto ou material do signo, é audível e/ou legível, ele está no plano da expressão. Já o significado é o aspecto imaterial, conceitual do signo. Portanto, podemos afirmar que o significante seria o desenho e a legenda desse desenho, e o significado seria a interpretação mental, conceitual e de conteúdo que o leitor tem ao interpretar o significante, ao resultado dessa interpretação dá-se o nome de significação e o processo para chegar a significação denomina-se decodificação.

É essa relação entre o significante e o significado que levamos em consideração no momento de propormos o indicador Legenda, como apresentaremos adiante. Nesse sentido, organizar as aulas a partir do Pensamento Espacial coloca os alunos em situação de acionar as regiões cerebrais permitindo o desenvolvimento de vários tipos de habilidades do Pensamento Espacial (Gersmehl, 2008). A figura 2 abaixo nos clarifica em relação ao significado e organização das habilidades espaciais, do Pensamento Espacial e da alfabetização espacial.

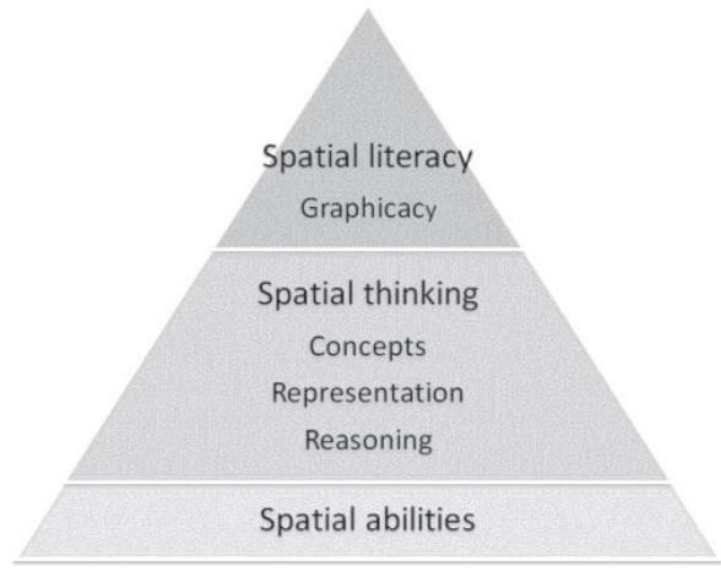

Figura 2. Um esquema conceitual de Pensamento Espacial e os termos relacionados. Fonte: Wakabayashi e Ishikawa (2011).

Wakabayashi e Ishikawa (2011) apresentam a diversidade de termos relacionados à alfabetização espacial, ao Pensamento Espacial e às habilidades espaciais. E definem a alfabetização espacial como a capacidade de Graphicacy e apresentam a definição que encontram no dicionário de inglês Oxford "como a habilidade para entender e usar o mapa ou gráfico". Segundo esses autores as representações internas e externas precisam ser esclarecidas porque estão relacionadas à estrutura do pensamento. A representação espacial interna está preocupada com a formação e manipulação das imagens espaciais na mente, as quais requerem habilidades espaciais de visualização, orientação e relações espaciais. A representação espacial externa refere-se a organização, compreensão e comunicação da informação por meio de mapas, imagens e gráficos (Wakabayashi e Ishikawa, 2011).

De acordo com o exposto acima, poderíamos concluir que a alfabetização espacial requer dominar habilidades de visualização, orientação, de relações espaciais e de representação das informações por meio de mapas, imagens e gráficos. Contudo, Bednarz e Kemp (2011) corroboram com Goodchild (2006) e ampliam a definição de Alfabetização Espacial, considerando-na como:

[...] uma ampla gama de perspectivas, conhecimentos, habilidades e estratégias cognitivas, ou organização mental. A aplicação delas pode ser caracterizada como o Pensamento Espacial; o raciocínio espacial é uma sub-habilidade do Pensamento Espacial, distinguido como os processos específicos aplicados ao pensar espacialmente para resolver problemas e tomar decisões. A alfabetização espacial, presumimos, é a consequência do pensamento e do raciocínio espacial [...]. o Pensamento Espacial, é definido assim, como um processo de funcionamento, o qual facilita o desenvolvimento da alfabetização espacial (Bednarz e Kemp, 2011, p. 20). ${ }^{8}$

Sendo assim, para atingirmos a alfabetização espacial precisamos desenvolver as habilidades do Pensamento Espacial, bem como o Raciocínio Espacial, o qual é a aplicação do Pensamento Espacial para resolver problemas e tomar decisões (Bednarz e Kemp, 2011). As habilidades do Pensamento Espacial são, portanto, a base para o desenvolvimento do Pensamento Espacial - e seus termos como conceitos espaciais, representação espacial e raciocínio espacial - o domínio de todo esse processo, o saber usar onde, como e quando esses conceitos, essas representações e o raciocínio espacial demonstram que a pessoa está alfabetizada espacialmente.

Nesse sentido, para avaliarmos se uma pessoa está alfabetizada espacialmente ela precisa ter desenvolvido as habilidades do Pensamento Espacial e saber aplicá-las, demonstrando por consequência o domínio do Pensamento Espacial. Na escola, ocorre quando o professor está trabalhando com leitura de mapas, com percurso, com mapas mentais, por exemplo, desde as series iniciais do ensino fundamental. Dessa forma, no item a seguir, apresentamos os Indicadores da Alfabetização Cartográfica e Espacial, os quais contribuíram na elaboração dos Indicadores da Alfabetização Científica para a Educação Geográfica apresentados na nossa pesquisa de Mestrado. 


\section{Desenhando os indicadores da alfabetização cartográfica e espacial}

A importância de elaborarmos indicadores está na definição do que se almeja ensinar, possibilitando ao longo das aulas e das intervenções didáticas realizadas avaliar como os alunos estão aprendendo e como eles constroem o conceito proposto nas atividades. Assim, os indicadores estabelecem uma gama de conceitos e habilidades que são cruciais para o conhecimento científico estudado, define o significado desses conceitos e habilidades e permite ao professor compreender e estabelecer o que de fato é importante ensinar e qual é a expectativa de aprendizagem. Nessa perspectiva, elaboramos os indicadores a partir da proposta de Sasseron (2008), como pode ser visto na tabela 1.

Tabela 1. Síntese da relação entre os Indicadores da AC e os Indicadores da ACEG

\begin{tabular}{|c|c|c|}
\hline $\begin{array}{l}\text { Grupos de indicadores } \\
\text { relacionados }\end{array}$ & $\begin{array}{c}\text { Indicadores de } \\
\text { Alfabetização Científica }\end{array}$ & $\begin{array}{c}\text { Indicadores da } \\
\text { Alfabetização } \\
\text { Científica da Educação } \\
\text { Geográfica }\end{array}$ \\
\hline \multirow{3}{*}{$\begin{array}{l}\text { Ao trabalho com os } \\
\text { dados obtidos em uma } \\
\text { investigação }\end{array}$} & $\begin{array}{l}\text { Seriação de } \\
\text { Informações }\end{array}$ & $\begin{array}{l}\text { Localização, Alfabeto } \\
\text { cartográfico (área, } \\
\text { ponto e linha) }\end{array}$ \\
\hline & $\begin{array}{l}\text { Organização de } \\
\text { informações }\end{array}$ & Visão vertical \\
\hline & $\begin{array}{l}\text { Classificação de } \\
\text { Informações }\end{array}$ & Legenda \\
\hline \multirow[t]{2}{*}{$\begin{array}{c}\text { À estrutura do } \\
\text { pensamento que } \\
\text { molda os registros } \\
\text { escritos dos alunos e a } \\
\text { elaboração dos mapas } \\
\text { mentais e dos croquis } \\
\text { cartográficos. }\end{array}$} & Raciocínio Lógico & $\begin{array}{l}\text { É o entendimento } \\
\text { da espacialização } \\
\text { dos elementos } \\
\text { considerando o tempo } \\
\text { como um dos fatores da } \\
\text { organização espacial. } \\
\text { Esse indicador também } \\
\text { corresponde a forma } \\
\text { de como os alunos } \\
\text { realizam seus registros, } \\
\text { seja por meio da } \\
\text { produção textual, ou } \\
\text { seja, na elaboração de } \\
\text { mapas e de croquis. }\end{array}$ \\
\hline & Raciocínio Proporcional & Escala \\
\hline
\end{tabular}

Fonte: Sasseron (2008); Risette (2017).

Esse quadro refere-se aos indicadores que encontramos quando relacionamos a Alfabetização Cartográfica com a Alfabetização Espacial. A ideia é apresentar como organizamos e definimos esses indicadores, para aprofundarmos a reflexão e o debate crítico sobre nossa exposição.
Os indicadores Localização e Alfabeto Cartográfico compõem a capacidade de seriar informações, um indicador da Alfabetização Científica relacionado "ao estabelecimento de bases para a ação investigativa. Não prevê, necessariamente, uma ordem que deva ser estabelecida para as informações: pode ser uma lista ou uma relação dos dados trabalhados ou com os quais se vá trabalhar" (Sasseron, 2008, p.67). Dessa forma, a localização indica a possibilidade de avaliação do processo de aprendizagem quando o estudante sabe se orientar no espaço, seja por meio de instrumentos como mapas, imagens de satélite, fotografias aéreas etc., ou por meio dos pontos de referência, levando em consideração a localização de forma relativa, a qual considera os elementos que o aluno é capaz de reconhecer no espaço.

As formas de representação por meio do Alfabeto Cartográfico (área, ponto e linha) nos orienta a respeito da ordenação da representação do fenômeno e/ou do Lugar no espaço. Diz respeito a escolha dos alunos no momento de simbolizar os objetos no papel, sendo esses objetos um dado da realidade. 0 desenvolvimento do alfabeto cartográfico significa possibilitar a descrição do espaço por meio da representação cartográfica. Além disso, o alfabeto cartográfico é mais do que as formas de representações espaciais, pois para ser apreendido é necessário ter o raciocínio lógico e o raciocínio proporcional bem desenvolvidos, e ainda ter noção da semiologia gráfica.

Contudo, na construção que estamos propondo assumimos que todos os indicadores necessitam do raciocínio lógico para serem assimilados, e consideramos a escala como um outro indicador, o qual apreende o raciocínio e o desenho proporcionais; e a legenda foi estabelecida como o indicador fundamentado na classificação das informações, incorporando a semiologia gráfica na relação entre significante e significado. Assim, não propomos a redução do alfabeto cartográfico somente às representações, estamos, na verdade, sugerindo que o domínio do alfabeto cartográfico possa ser identificado nas representações realizadas pelos alunos, demonstrando por meio de imagens e desenhos como eles descrevem o lugar, ou o fenômeno, ou o objeto estudado, elencando assim quais símbolos traduzem melhor os objetos quais eles desejam representar.

O próximo indicador, Visão Vertical, está ligado ao indicador da Ac denominado de Organização das informações, pois ele

[...] surge quando se procura preparar os dados existentes sobre o problema investigado. Este indicador pode ser encontrado durante o arranjo das informações novas ou já elencadas anteriormente e ocorre tanto no início da proposição de um tema quanto na retomada de uma questão, quando idéias são relembradas (Sasseron, 2008, p.67).

A Visão Vertical compreende a capacidade de ler mapas, basicamente, pois “todo mapa é uma visão vertical” (Simielli, 2007, p.90). O processo de desenvolvimento dessa habilidade é indicado quando o aluno con- 
segue representar objetos de forma bidimensional e realizar o caminho inverso, seria uma atividade que partisse da realidade para a representação no mapa e do mapa para a representação na forma de maquete, por exemplo. A capacidade de realizar esse vai e vem entre as representações bi e tridimensionais torna o aluno apto na visão vertical. Esse indicador compreende a organização dos objetos simbolizados de acordo com o alfabeto cartográfico para serem representados no papel. Ou seja, a visão vertical é a habilidade de ordenar os símbolos no processo de representação espacial.

Associamos a Legenda ao indicador referente à classificação de informações, o qual

[...] aparece quando se busca estabelecer características para os dados obtidos. Por vezes, ao se classificar as informações, elas podem ser apresentadas conforme uma hierarquia, mas o aparecimento desta hierarquia não é condição sine qua non para a classificação de informações. Caracteriza-se por ser um indicador voltado para a ordenação dos elementos com os quais se trabalha (Sasseron, 2008, p.67).

Nesse sentido, a classificação de informações prevê uma hierarquia e uma ordem dos elementos, sendo a primeira um atributo não obrigatório. O indicador Legenda pressupõe o desenvolvimento da capacidade de abstração dos elementos da realidade e de generalizá-los, classificando-os e estabelecendo as relações entre o significante e o significado para a construção da Legenda. A construção da legenda envolve o domínio da habilidade de organizar a informação que se quer comunicar, é a organização do texto do mapa por meio dos símbolos.

O Raciocínio lógico compreende o modo como as ideias são desenvolvidas e apresentadas e está diretamente relacionado à forma como o pensamento é exposto. Raciocinando sobre o Pensamento Espacial, todas as habilidades do Pensamento Espacial exigem o desenvolvimento do raciocínio lógico, ele pode ser observado nos registros escritos e nos mapas produzidos pelos alunos. Além disso, ressaltamos que o desenvolvimento do Raciocínio lógico para a Geografia é fundamental para a compreensão da organização dos elementos no espaço e no tempo, e é essa relação que iremos avaliar por meio desse indicador.

A Escala é observada quando percebemos que os alunos conseguem estabelecer as relações de proporção entre os objetos, essa habilidade está, portanto, articulada com o indicador raciocínio proporcional proposto para o desenvolvimento da Alfabetização Científica, pois leva em consideração as variáveis dos fenômenos, dado que alguns dependem da relação escalar para serem analisados, além de compreendermos que os fenômenos são espacializados de forma interdependentes entre si. Nesse sentido, o indicador escala pode aparecer nos mapas mentais e croquis elaborados pelos estudantes, quando eles conseguem desenhar a casa deles em um tamanho proporcional à dimensão da escola, por exemplo.

\section{Reflexões}

Ao longo desse trabalho podemos afirmar que a reflexão a respeito dos indicadores para a Educação Geográfica é extremamente desafiadora, porque o campo teórico da geografia, os conceitos e as construções epistemológicas abrem muitos leques de possibilidades para caminharmos sobre essa questão. No entanto, diante do trabalho da sala de aula e do interesse em motivar os alunos a apreender, desenvolver os indicadores da Educação Geográfica é uma tarefa mais do que necessária, pois se desenha os objetivos de ensino e os parâmetros de avaliação, conduzindo o professor para uma atuação mais assertiva em sala de aula a partir de um instrumento que pode ser moldado de acordo com as escolhas epistemológicas e didáticas do próprio professor.

O Pensamento Espacial traz uma compreensão ampla e pertinente ao estudo geográfico conferindo vínculos importantes com a produção teórica brasileira a respeito da Alfabetização Cartográfica. A Alfabetização Científica reforça o foco na aprendizagem e nos orienta a respeito das estratégias didáticas que usaremos para alcançar tal objetivo. Assim, entender como o pensamento espacial se organiza no desenvolvimento cognitivo e traduzir esse raciocínio em expectativas de aprendizagem relacionadas ao saber fazer científico da geografia nos apresenta como uma rede de conceitos que vislumbra muitos desdobramentos quais merecem que nos debrucemos mais sobre essas teorias e metodologias para ampliarmos nossa contribuição para a Educação Geográfica.

Diante disso, desenvolver e propor Indicadores da Alfabetização Cartográfica é só uma parte da convergência existente entre a Alfabetização Científica, o Pensamento Espacial e a Alfabetização Cartográfica. Essa articulação, portanto, segue sendo objeto de nosso estudo com intuito de aprofundarmos cada vez mais nosso entendimento e nossas propostas para ensinar e aprender geografia.

\section{Referências}

Almeida, R. (Ed.). (2010). Cartografia Escolar. São Paulo: Contexto.

Bednarz, S. e Kemp, K. (2011). Understanding and nurturing spatial literacy. Procedia-Social and Behavioral Sciences, 21, 18-23.

Castellar, S. (2000). Alfabetização em Geografia. Espaços da Escola, 10(37), 29-46.

Castellar, S. (2017). Cartografia Escolar e o Pensamento Espacial - fortalecendo o conhecimento geográfico. Revista Basileira de Educação em Geografia, 7(13), 207-232. 
Duarte, R. (2017). A linguagem cartográfica como suporte ao desenvolvimento do pensamento espacial dos alunos na educação básica. Revista Basileira de Educação em Geografia, 7(13), 187-206.

Gersmehl, P. (2008). Teaching geography. New York: The Guilford Press.

Golledge, R. (2002). The nature of geographic knowledge. Annals of the Association of American Geographers, 92(1), 1-14.

Goodchild, M. (2006). The fourth R? Rethinking GIS Education. Esri Understanding our world. Disponível em: http://www.esri.com/news/ arcnews/fall06articles/the-fourth-r.html.

National Research Council (NRC). (2006). Learning to think spatially. Washington, D. C.: The National Academies Press.

Risette, M. (2017). Pensamento Espacial e Raciocínio Geográfico: Uma proposta de indicadores para a Alfabetização Científica na Educação Geográfica (tese de mestrado). Universidade de São Paulo, São Paulo, Brasil.
Sasseron, L. (2008). Alfabetização Científica no Ensino Fundamental: Estrutura e Indicadores desse processo em sala de aula (tese de doutorado). Universidade de São Paulo, São Paulo, Brasil.

Sasseron, L. e Carvalho, A. (2008). Almejando a Alfabetização Cietífica no Ensino Fundamental: A proposição e a procura de indicadores do processo. Investigações em Ensino de Ciências, 13(3), 333-352.

Simielli, M. (2007). O mapa como meio de comunicação e alfabetização cartográfica. Em R. Almeida (Ed.), Cartografia Escolar (pp. 71-94). São Paulo: Contexto.

Wakabayashi, Y. e Ishikawa, T. (2011). Spatial thinking in geographic information science: a review of past estudies and prospects for the future. Procedia Social and Behavioral Sciences, 21, 304-313. 